\title{
A Randomized, Multiple-dose, Multicenter, Comparative Parallel Study to Evaluate the Safety and Efficacy of Intravenous Infusion of Rituximab (Hetero) and Reference Medicinal Product (Rituximab, Roche) in Indian Patients of Non-Hodgkin's Lymphoma (HERILY)
}

\begin{abstract}
Objective: To compare the antitumor efficacy, safety, and pharmacodynamic (PD) characteristics of Hetero-rituximab (test) with reference medicinal product (rituximab, Roche) in non-Hodgkin's lymphoma. Patients and Methods: One hundred and thirty-five patients with diffuse large B-cell lymphoma (DLBCL) were randomized to receive intravenous infusion of either test or reference product. Efficacy (best overall response [BOR] rate [primary end point]), safety, PD (CD19), and immunological assessments (secondary end points) were done at the end of cycle 3 and cycle 6 . Results: At the end of 6 cycles, BOR rate was $73.47 \%$ in Hetero-rituximab test arm compared to the $69.09 \%$ in reference arm. Anti-rituximab antibodies were found to be negative at cycle 3 and cycle 6 for all patients. Patients treated with Hetero-rituximab show a significant depletion in CD19+ cell which was comparable with reference drug. Safety and immunogenic potential of the test drug was comparable to the reference drug in the patients of DLBCL. Conclusion: BOR rate at cycle 3, cycle 6 , and end of the study lies within the prespecified limit for noninferiority which concludes that test product is therapeutically noninferior to reference medicinal product.
\end{abstract}

Keywords: Diffuse large B-cell lymphoma, non-Hodgkin's lymphoma, rituximab

\section{Introduction}

Diffuse large B-cell lymphoma (DLBCL) which is the most common of non-Hodgkin's lymphoma (NHL) which accounts for $30-35 \%$ of all cases. The current standard of the treatment for DLBCL includes cyclophosphamide, doxorubicin, vincristine, and prednisone (CHOP). Addition of rituximab to $\mathrm{CHOP}$ has greatly improved patient outcomes with DLBCL. ${ }^{[1]}$ Rituximab is the first genetically engineered chimeric (murine-human) monoclonal antibody (mAb) against the CD20 antigen for the treatment of cancer recommended at the dosage of $375 \mathrm{mg} / \mathrm{m}^{2} /$ infusion, weekly for 4 weeks. Because of its human component, rituximab has low immunogenicity. ${ }^{[2]}$ For approval by the US Food and Drug Administration, multiple studies were conducted internationally. In a Phase III (GELA) study, the rate of complete response (CR) was significantly higher $(76 \%$ vs. $63 \%)$ in the group that received $\mathrm{CHOP}$ plus rituximab than in the group that received $\mathrm{CHOP}$ alone.

This is an open access journal, and articles are distributed under the terms of the Creative Commons Attribution-Non Commercial-ShareAlike 4.0 License, which allows others to remix, tweak, and build upon the work non-commercially, as long as appropriate credit is given and the new creations are licensed under the identical terms.

For reprints contact: reprints@medknow.com
Similarly, in another study (MabThera International Trial), patients assigned chemotherapy and rituximab had increased 3-year event-free survival compared with those assigned chemotherapies alone.

Rituximab was approved by the Food and Drug Administration on November 26, 1997 (and by the European Union on June 2, 1998) for the indication of follicular NHL. ${ }^{[3]}$ In 2014, a subcutaneous formulation of Rituxan ${ }^{\circledR}$ (rituximab) was further approved by the European Commission for the treatment of both follicular lymphoma and DLBCL. ${ }^{[4]}$

In India, safety of biosimilar rituximab is already established in Indian patients with two biosimilar products readily available in market. As per the Guidelines of Central Drugs Standard Control Organization, comparative clinical trials are critical to demonstrate the similarity in efficacy and safety profiles between the similar biologic and reference biologic. Hence, Phase III, randomized noninferiority trial was

How to cite this article: Advani S, Biswas G, Sinha S, Rayala NN, Chary S, Thakur P, et al. A randomized, multiple-dose, multicenter, comparative parallel study to evaluate the safety and efficacy of intravenous infusion of rituximab (Hetero) and reference medicinal product (Rituximab, Roche) in Indian patients of nonhodgkin's lymphoma (HERILY). Indian J Med Paediatr Oncol 2018;39:316-20.

\section{Suresh Advani, Ghanashyam \\ Biswas ${ }^{1}$, Shubhadeep Sinha², Neetu Naidu Rayala², Sreenivasa Chary², Pankaj Thakur ${ }^{2}$, Anushrita ${ }^{2}$, Santanu Tripathi ${ }^{3}$, Vamsi Krishna Bandi $^{2}$}

Department of Medical Oncology, Jaslok Hospital and Research Centre, Mumbai, Maharashtra, ' Sparsh Hospitals and Critical Care Pvt. Ltd., Bhubaneswar, Orissa, ${ }^{2}$ Hetero Labs Limited-Corporate, Hyderabad, Telangana, ${ }^{3}$ Department of Clinical and Experimental Pharmacology, School of Topical Medicine, Kolkata, West Bengal, India

Address for correspondence: Dr. Shubhadeep Sinha, Hetero Labs Limited-Corporate, 7-2-A2, Industrial Estates, Sanath Nagar, Hyderabad - 500018 , Telangana, India.

E-mail:SD.Sinha@heterodrugs. com

Access this article online Website: www.ijmpo.org DOI: 10.4103/ijmpo.ijmpo_25_17 Quick Response Code:

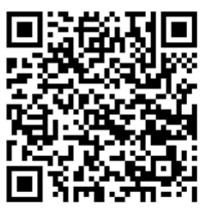


conducted in DLBCL patients to compare the efficacy and safety of intravenous infusion of Hetero's test and reference medicinal product (rituximab, Roche).

\section{Materials and Methods}

\section{Study design and participants}

This was a Phase III, randomized, multiple-dose, multicenter, comparative, parallel study to evaluate the efficacy, safety of intravenous infusion of Hetero-rituximab (test), and reference medicinal product (Roche, rituximab) in newly diagnosed DLBCL NHL.

The study was carried out from September 2013 to August 2015 at 36 sites of India. Out of 135 patients randomized, 105 patients completed the study. Primary efficacy analysis was carried out on Intention to Treat (ITT) set $(n=104)$.

The study protocol was approved by the office of Drug Controller General of India and Ethics Committees. Independent ethics committees or institutional review boards at participating sites approved the protocol. The study was registered to Clinical Trial Registry - India (CTRI) before initiation of the study (CTRI Registration No: CTRI/2013/08/003921). The study was conducted in accordance with the Declaration of Helsinki (2000) and the International Conference on Harmonisation Guidelines for Good Clinical Practice. Written informed consent was obtained from patients or their legally authorized representatives before initiation of any trial procedure.

Key inclusion criteria were male or female $\geq 18$ years and $\leq 65$ years of age (both inclusive), histologically confirmed CD20-positive, newly diagnosed DLBCL NHL (Stage I, II, III, IV) by Ann Arbor (Cotswold modification), or previously untreated patients with stage III-IV follicular lymphoma in combination with chemotherapy, patients who are eligible for rituximab and CHOP, patients with at least one measurable lesion as per the International Working Group response criteria $^{[1]}$ for malignant lymphoma, adequate liver, renal, cardiac, and hematological function, participants with a performance status of 0-2 according to the Eastern Cooperative Oncology Group, and life expectancy $>6$ months.

\section{Study treatments}

All eligible patients after fulfilling eligibility criteria were randomized to open-label treatment with either Hetero-rituximab (test drug) or the reference medicinal product (reference drug) at a $1: 1$ ratio or $375 \mathrm{mg} / \mathrm{m}^{2}$ was administered on day 1 of each chemotherapy cycle in combination with CHOP for 6 cycles. Premedication consisting of an antipyretic and an antihistaminic, for example, paracetamol and diphenhydramine or prednisolone or as per institutional standard was administered before each infusion of Investigational Medicinal Product (IMP).

\section{End point assessment}

Primary efficacy end point of the study was calculated on best overall response (BOR) rate at the end of cycle 3 and cycle 6 . Primary efficacy analysis was performed on patients with BOR rate which was defined as patients with response of CR and partial response (PR). CR and PR were defined by the IWG criteria and evaluated by an independent radiologist in a blinded manner. Computed tomography, magnetic resonance imaging, and/or fluorodeoxyglucose-positron emission tomography were conducted at screening, before the use of study drug; the last week of treatment cycles 3,6 , or the end of treatment visit. The secondary evaluation was based on the evaluation of safety, immunogenicity, and clinical pharmacodynamics (PD). Safety was measured by adverse events (AEs) by monitoring of significant clinical signs and symptoms and laboratory abnormalities during treatment. The blood and urine tests were performed at an accredited central laboratory. Safety of the treatment regimens was evaluated among patients who received $\geq 1$ dose of study drug. AEs were coded using the Medical Dictionary for Regulatory Activities version 15.0 (Developed by ICH), and AEs were recorded and graded according to the Common Terminology Criteria for AEs version 4.0. Immunogenicity was evaluated by assessing blood serum for the presence of anti-rituximab antibodies in all patients at the end of cycle 3 and at the end of cycle 6 at an accredited central laboratory. Clinical PD was evaluated by circulating B-cell measurements at an accredited central laboratory, using $\mathrm{CD} 19+$ as a surrogate marker for B-cells expressing CD20 at the end of cycle 3 and at the end of cycle 6 .

An independent external data safety monitoring board was implemented at the beginning of the study for review of all available safety data on an ongoing basis as per the data safety monitoring board charter.

\section{Statistical analyses}

For a comparison of two independent binomial proportions using Fisher's exact test with a one-sided significance level of 5\%, considering the proportions $94 \%$ based on the literature and assumed proportion as $75 \%$, a sample size of 52 per arm (104 completers for two arms) was required to achieve power of $80 \%$. Adequate Indian patients of DLBCL were screened and randomized to ensure at least 104 evaluable patients. Randomization schedule was generated using SAS version 9.3 before the commencement of the study. Block randomization of size 2 in ratio of 1:1 (test: reference) was generated, and balanced treatment allocation within block was ensured at the time of randomization generation. To evaluate safety, a set was made for all patients who received at least one dose of study drug. All statistical analysis was performed using $\mathrm{SAS}^{\circledR}$ Version 9.3 (SAS Institute Inc., USA). 


\section{Results}

\section{Efficacy}

At the end of the $6^{\text {th }}$ cycle, 49 patients in test arm and 55 patients in reference arm were evaluable for DLBCL. The result of the study indicates that proportion of patients with best BOR (CR + PR) is $73.47 \%$ in test compared to the $69.09 \%$ in reference at the end of the cycle 6 . These results show that the lower limit of $97.06 \%$ confidence interval $(-14.93 \%, 23.69 \%)$ for the difference between test and reference proportions of best BOR at cycle 6 lies within the prespecified limit for noninferiority (lower limit $>-20 \%$ ) [Table 1]. Primary efficacy analysis was carried out on ITT set (efficacy analysis set in 104 patients).

In addition, $\mathrm{CR}$ rate was $40.82 \%(n=20)$ in patients receiving test compared to $25.45 \%(n=14)$ patients received reference while PR rates were $32.65 \%(n=16)$ and $43.64 \%(n=24)$ for the DLBCL patients who were exposed to test and reference formulations, respectively.

The primary end point is presented in Table 1 .

\section{Safety and tolerability}

There were a total of 832 treatment emergent adverse events (TEAEs) out of which 451 were reported after receipt of reference medicinal product and 381 were reported after receipt of test product. Two predose AEs occurred in the entire course of the study. Nearly 832 TEAEs were reported by 117 patients during the conduct of study. Of these 832 TEAEs, 459 AEs were mild, 278 AEs were moderate, and 95 AEs were severe in nature.

A total of 53 serious adverse events (SAEs) including one predose SAE were reported during the conduct of study. Of these, outcome of 11 SAEs was reported as death. Out of the total reported 53 SAEs, 27 SAEs were reported in patients under reference group, 25 SAEs were reported in patients under test group, and one SAE was reported predose phase of the clinical trial.

\section{Pharmacodynamics and immunogenicity}

Rituximab treatment leads to decrease in the CD19 counts in DLBCL patients. In both study arms (test as well as reference), decrease in the CD19 counts started from cycle 3 [Table 2] and was maintained throughout the treatment duration till the completion of the treatment, i.e., at the end of the cycle 6 . The patients treated with Hetero-rituximab show a significant depletion in CD19+ cell which was comparable with reference rituximab and also with the values previously reported for reference.

\section{Discussion}

We compared the efficacy, safety, and pharmacodynamic characteristics of intravenous infusion of rituximab (test and reference) in DLBCL patients. Our study demonstrated that test rituximab (Hetero's product) was found noninferior to reference rituximab (developed by Roche). Our primary analysis in the ITT population met the prespecified noninferiority margin of lesser than $-20 \%$. The efficacy and safety of rituximab in DLBCL patients had been studied in several randomized clinical studies in the past. The efficacy results of our study in patients with DLBCL are consistent with those reported in literature. ${ }^{[4,5]}$ Several pivotal clinical trials have demonstrated the benefit of adding rituximab to the chemotherapy regimen versus chemotherapy alone. The randomized Phase III trial conducted by Groupe d'Etude des Lymphomes de l'Adulte in elderly (aged 60-80 years) patients with previously untreated DLBCL showed a significantly higher $\mathrm{CR}$ rate $(76 \%$ vs. $63 \% ; P=0.005)$ and longer event-free (not reached vs. 13 months; $P<0.001$ ) and overall $(P=0.007)$ survival with, respectively, rituximab plus CHOP versus CHOP alone. ${ }^{[1]}$

Finding of ORR in the present study seems very similar to other studies, ${ }^{[6-8]}$ where most of the patients in both the study arms have significantly reduced tumor mass. The ORR for test was $73.47 \%$ while $69.09 \%$ for reference rituximab arm. In a meta-analysis, results of several studies evaluating rituximab $375 \mathrm{mg} / \mathrm{m}^{2}$ once weekly for 4 weeks in patients with indolent forms of B-cell NHL (primarily follicular and small lymphocytic lymphomas) showed objective response (OR) rates in the range of $40 \%-60 \%$ in those receiving the drug for relapsed or refractory indolent B-cell NHL and slightly higher $(50 \%-70 \%)$ for those receiving rituximab as first-line therapy. Other combinations such as CHOP and fludarabine-containing regimens have also given promising results with a consistent OR around $95 \%{ }^{[9]}$

There were no clinically relevant changes in vital signs or biochemical parameters throughout the study. No significant differences were observed between both the treatment and reference groups. Overall, safety and tolerability of rituximab in this study is in agreement with other studies with rituximab where similar tolerability was reported. ${ }^{[10-12]}$

In the current study, none of the analyzed samples, either in the test or reference group, was positive for anti-rituximab antibodies, i.e., immunogenicity was not observed with the study drugs. The results were consistent with the study conducted by Florez et al. in which none of

\begin{tabular}{lccccc}
\hline & \multicolumn{4}{c}{ Table 1: Summary statistics of best overall response rate by treatment group (ITT, $\boldsymbol{n = 1 0 4 )}$} \\
\hline End point & $\begin{array}{c}\text { Test product } \\
(\boldsymbol{n}=\mathbf{4 9}), \boldsymbol{n} \mathbf{( \% )}\end{array}$ & $\begin{array}{c}\text { Reference product } \\
(\boldsymbol{n}=\mathbf{5 5}), \boldsymbol{n} \mathbf{( \% )}\end{array}$ & $\begin{array}{c}\text { Difference between proportions } \\
(\text { test vs. reference) } \mathbf{( \% )}\end{array}$ & $\begin{array}{c}\text { Confidence } \\
\text { Interval }\end{array}$ & $\begin{array}{c}\text { Acceptance } \\
\text { range }(\boldsymbol{\%})\end{array}$ \\
\hline BOR rate & $36(73.47)$ & $38(69.09)$ & 4.38 & $-14.93-23.69$ & Lower limit $(>-20)$ \\
\hline BOR
\end{tabular}

BOR - Best overall response; CI - Confidence interval, ITT - Intention to treat 


\begin{tabular}{|c|c|c|c|c|c|}
\hline Visit & Unit $(\mu \mathrm{l} / \%)$ & Statistics & Test product $(n=48)$ & Reference product $(n=57)$ & Total $(n=105)$ \\
\hline \multirow[t]{10}{*}{1} & \multirow[t]{5}{*}{$\mu \mathrm{l}$} & $n$ & 44 & 54 & 98 \\
\hline & & GMT & 4.47 & 4.87 & 4.69 \\
\hline & & $\mathrm{SD}$ & 382.14 & 11638.35 & 8640.92 \\
\hline & & Median & 112.50 & 109.00 & 109.50 \\
\hline & & Range: Minimum-maximum & $0.00-2434.00$ & $14.00-85685.00$ & $0.00-85685.00$ \\
\hline & \multirow[t]{5}{*}{$\%$} & $n$ & 45 & 55 & 100 \\
\hline & & GMT & 1.90 & 2.24 & 2.09 \\
\hline & & $\mathrm{SD}$ & 8.66 & 11.97 & 10.65 \\
\hline & & Median & 9.00 & 9.00 & 9.00 \\
\hline & & Range: Minimum-maximum & $0.00-47.00$ & $2.00-83.00$ & $0.00-83.00$ \\
\hline \multirow[t]{10}{*}{8} & \multirow[t]{5}{*}{$\mu 1$} & $n$ & 37 & 47 & 84 \\
\hline & & GMT & 1.78 & 1.87 & 1.83 \\
\hline & & $\mathrm{SD}$ & 6.42 & 22.62 & 17.54 \\
\hline & & Median & 0.00 & 0.00 & 0.00 \\
\hline & & Range: Minimum-maximum & $0.00-29.00$ & $0.00-121.00$ & $0.00-121.00$ \\
\hline & \multirow[t]{5}{*}{$\%$} & $n$ & 36 & 47 & 83 \\
\hline & & GMT & 0.80 & 0.78 & 0.79 \\
\hline & & $\mathrm{SD}$ & 14.64 & 3.34 & 9.92 \\
\hline & & Median & 0.00 & 0.00 & 0.00 \\
\hline & & Range: Minimum-maximum & $0.00-88.00$ & $0.00-17.00$ & $0.00-88.00$ \\
\hline \multirow[t]{10}{*}{13} & \multirow[t]{5}{*}{$\mu 1$} & $n$ & 29 & 29 & 58 \\
\hline & & GMT & 2.46 & 1.80 & 2.11 \\
\hline & & $\mathrm{SD}$ & 85.74 & 16.25 & 61.56 \\
\hline & & Median & 0.00 & 0.00 & 0.00 \\
\hline & & Range: Minimum-maximum & $0.00-463.00$ & $0.00-80.00$ & $0.00-463.00$ \\
\hline & \multirow[t]{5}{*}{$\%$} & $n$ & 29 & 29 & 58 \\
\hline & & GMT & 0.89 & 0.73 & 0.81 \\
\hline & & $\mathrm{SD}$ & 3.19 & 1.99 & 2.64 \\
\hline & & Median & 0.00 & 0.00 & 0.00 \\
\hline & & Range: Minimum-maximum & $0.00-17.00$ & $0.00-10.00$ & $0.00-17.00$ \\
\hline
\end{tabular}

GMT - Geometric mean titer; SD - Standard deviation

the patients of the DLBCL treated with rituximab showed immunogenicity. ${ }^{[13]}$ However, in a developmental study of rituximab conducted by Roche Drugs Limited in patients with low-grade or follicular NHL, anti-human anti-chimeric antibody was detected in 4 out of $356(1.1 \%) .^{[2]}$ Thus, the available data suggest that immunogenic potential of the test drug was comparable to the reference drug DLBCL patients and is also consistent to the previously conducted studies with the similar molecule.

Rituximab treatment leads to decrease in the CD19 count in DLBCL patients. In both the test as well as reference arms, decrease in the CD19 counts was observed. It was started from cycle 3 and was maintained throughout the treatment duration till the completion of the treatment, i.e., at the end of the cycle 6 .

Rituximab is a chimeric $\mathrm{mAb}$, which binds with high affinity to the transmembrane antigen CD20. It exerts its therapeutic effect by binding to $\mathrm{CD} 20$ antigen and then promoting B-cell lysis through several possible mechanisms such as complement-mediated cytotoxicity, antibody-dependent cellular cytotoxicity, and induction of apoptosis. ${ }^{[14-16]}$ Since rituximab binds to CD20 antigen, its presence in blood samples can interfere with assay of CD20 cells. Hence, rituximab administration can confound CD20 assay measurements. ${ }^{[1]}$ Moreover, CD19 expression mirrors CD20 expression and can therefore serve as a surrogate marker in patients with circulating rituximab. ${ }^{[3]}$ Many studies have also established that rituximab leads to decrease in circulating CD19+ cells in CD20+ NHL and in autoimmune disorders. ${ }^{[17]}$ In a previously conducted study in patients with NHL, administration of rituximab resulted in depletion of circulating and tissue-based B-cells. Among 166 patients randomized, circulating CD19-positive B-cells were depleted within the first 3 weeks with sustained depletion for up to 6-9 months' posttreatment in $83 \%$ of the patients. ${ }^{[18]}$ This was also proved by a study conducted for indication other than NHL such as in patients with rheumatoid arthritis. It was seen that treatment with rituximab plus methotrexate resulted in a rapid and near complete depletion (median postinfusion B-cell count was $1 \mathrm{cell} / \mu \mathrm{L}$ ) of peripheral CD19 B-cells, with $>95 \%$ of patients having counts below 10 cells $/ \mu \mathrm{L}$ by the end of the second infusion. Hence, the data suggest that DLBCL 
patients treated with test had a significant depletion in CD19+ cell which was comparable with reference and also with the values previously reported for reference rituximab.

\section{Conclusion}

Rituximab manufactured by Hetero Drugs Limited was therapeutically noninferior in terms of efficacy, pharmacodynamics, safety, tolerability, and immunogenicity to the reference rituximab developed by Roche ${ }^{\circledR}$ in patients of DLBCL.

\section{Acknowledgment}

This study was sponsored by Hetero Drugs Limited, India and all the study related materials including study drugs were provided by Hetero Drugs Limited, India. Authors would like to thank all participating investigators as listed on CTRI and their staff for all support and all study participants for their valuable participation in this study and cooperation. Clinical trial registry number: CTRI/2013/08/003921.

\section{Financial support and sponsorship}

Hetero Drugs Limited, India.

\section{Conflicts of interest}

There are no conflicts of interest.

\section{References}

1. Coiffier B, Gisselbrecht C, Bosly A. Ten Years' followup of the LNH98.5 Study, First Randomized Study Comparing R-CHOP to CHOP Chemotherapy in Patients with Diffuse Large B-cell Lymphoma. A GELA Study. Program and Abstracts of the $51^{\text {st }}$ American Society of Hematology Annual Meeting. New Orleans, Louisiana; 2009.

2. Leget GA, Czuczman MS. Use of rituximab, the new FDA-approved antibody. Curr Opin Oncol 1998;10:548-51.

3. Rituximab for the First-Line Treatment of Stage III-IV Follicular Lymphoma, NICE Technology Appraisal Guidance [TA243]; 25 January, 2012. Available from: http://www.nice.org.uk/guidance/ TA243/chapter/3-The-technology. [Last accessed on 2016 Feb 20].

4. Media Release: Roche's new time-saving subcutaneous formulation of MabThera approved in Europe for the treatment of common forms of non-Hodgkin Lymphoma; 2014; Available

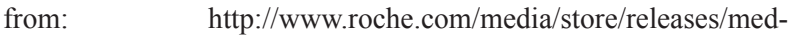
cor-2014-03-28.htm.

5. Australian Public Assessment Report for Rituximab. PM-2009-00656-3-4. MabThera Rituximab Roche Products Pty Ltd.; 19 February, 2010. Available from: https://www.tga.gov.au/ sites/default/files/auspar-rituximab.pdf. [Last accessed on 2016 Mar 14].

6. Ogura M, Morishima Y, Kagami Y, Watanabe T, Itoh K, Igarashi $\mathrm{T}$, et al. Randomized phase II study of concurrent and sequential rituximab and $\mathrm{CHOP}$ chemotherapy in untreated indolent B-cell lymphoma. Cancer Sci 2006;97:305-12.

7. Czuczman MS, Grillo-López AJ, White CA, Saleh M, Gordon L, LoBuglio AF, et al. Treatment of patients with low-grade B-cell lymphoma with the combination of chimeric anti-CD20 monoclonal antibody and CHOP chemotherapy. J Clin Oncol 1999; 17:268-76.

8. Product Information of MABTHERA $^{\circledR}$, Rituximab (rch), Attachment 1: Product information for AusPAR. PM-2012-04453-1-4. (CAS registry number: 174722-31-7). MabThera SC Rituximab Roche Products Pty Ltd.; 4 September, 2014. Available from: https://www.tga.gov.au/sites/default/files/ auspar-rituximab-140904-pi.pdf. [Last accessed on 2017 Jan 16].

9. Plosker GL, Figgitt DP. Rituximab: A review of its use in non-Hodgkin's lymphoma and chronic lymphocytic leukaemia. Drugs 2003;63:803-43.

10. Martinelli G, Schmitz SF, Utiger U, Cerny T, Hess U, Bassi S, et al. Long-term follow-up of patients with follicular lymphoma receiving single-agent rituximab at two different schedules in trial SAKK 35/98. J Clin Oncol 2010;28:4480-4.

11. Hainsworth JD, Litchy S, Shaffer DW, Lackey VL, Grimaldi M, Greco FA, et al. Maximizing therapeutic benefit of rituximab: Maintenance therapy versus re-treatment at progression in patients with indolent non-Hodgkin's lymphoma - A randomized phase II trial of the Minnie Pearl Cancer Research Network. J Clin Oncol 2005;23:1088-95.

12. Berinstein NL, Grillo-López AJ, White CA, Bence-Bruckler I, Maloney D, Czuczman M, et al. Association of serum rituximab (IDEC-C2B8) concentration and anti-tumor response in the treatment of recurrent low-grade or follicular non-Hodgkin's lymphoma. Ann Oncol 1998;9:995-1001.

13. Florez A, Matteo TD, Fresnillo G, Tudela C, Seigelchifer M, Corley E, et al. Clinical pharmacokinetic (PK) and safety (Immunogenicity) of rituximab biosimilar RTXM83 in combination with chemotherapy $\mathrm{CHOP}$ in patients with diffuse large B-Cell lymphoma (DLBCL). Blood 2014;124:5472.

14. RITUXAN ${ }^{\circledR}$ (rituximab) Injection, for Intravenous Use. Highlights of Prescribing Information. Initial U.S. Approval; 1997. Available from: http://www.accessdata.fda.gov/ drugsatfda_docs/label/2010/103705s5311lbl.pdf. [Last revised on 2014 Feb 08].

15. Australian Public Assessment Report for Rituximab. PM-2009-01744-3-3. Roche Products Pty Ltd; September, 2010. Available from: http://www.tga.gov.au/pdf/auspar/ auspar-mabthera.pdf. [Last accessed on 2016 Feb 20].

16. Mabthera $100 \mathrm{mg}$ and $500 \mathrm{mg}$ Concentrate for Solution for Infusion, Mabthera ${ }^{\circledR}$ Summary of Product Characteristic. Available from: http://www.medicines.org.uk/emc/medicine/2570. [Last accessed on 2013 Dec 04].

17. Pescovitz MD. Rituximab, an anti-cd20 monoclonal antibody: History and mechanism of action. Am J Transplant 2006;6:859-66.

18. Maloney DG, Liles TM, Czerwinski C, Waldichuk J, Rosenberg J, Grillo-López A, et al. Phase I clinical trial using escalating single-dose infusion of chimeric anti-CD20 monoclonal antibody (IDEC-C2B8) in patients with recurrent B-cell lymphoma. Blood 1994;84:2457-66. 